\title{
Through Parents' Eyes: An Activist Visual Literacy Project
}

\author{
Sandra R. Schecter, Lorraine S. Otoide \\ York University, Canada
}

\begin{abstract}
This visual literacy study, embedded in an intergenerational instructional innovation at an urban primary-junior school in Ontario, Canada, used photography to ascertain caregivers, perceptions of their children's everyday experiences. Photographs, logs, and discussion sessions documented the culture-filtered understandings and sensibilities of caregivers as they reflected upon children's educational experiences in their newly adopted country. Beyond this anticipated function, these data sources served as conduits through which professional educators could access domains of knowledge related to spheres of influence in children's lives that are not normally discovered through standard schooling practices. Equally importantly, they helped immigrant parents to access, and better understand, the diverse resources that children call upon as they navigate various aspects of their Diaspora experiences. Thusly, the photographs functioned not simply as representational icons that substituted for verbal texts but also as heuristics that drove participants' thinking about the psychological and social worlds of immigrant students.
\end{abstract}

\section{Introduction}

This paper reports on the findings of a visual literacy study for linguistically diverse parents/caregivers and their children. The study was embedded within an intergenerational instructional innovation for families of students attending a primary-junior school in an urban setting in Ontario, Canada. We begin by situating the larger project and the embedded study within a community-referenced approach to problems of educational equity, and go on to outline the problem that initiated the unique data collection and analysis approach used in the study. We then describe the specific data collection and analysis methods used, situating these within an institutional ethnography approach. Next, we reveal the study's findings, grouped within thematic clusters. We discuss these findings in terms of what researchers and professional educators learned about: (a) ways in which immigrant parents are involved in the everyday lives of their children, (b) their perceptions of their children's schooling and broader socialization/adaptation experiences, and (c) how family and community norms and resources help to shape these experiences. We conclude with a discussion highlighting the role of the visual literacy strategy in enabling participants to work through and extend their understandings of aspects of cultural literacy that played crucial roles in children's lives and in fostering empathy between immigrant caregivers and professional educators.

\section{Schooling in a Context of Linguistic and Cultural Diversity}

Global migration has introduced an unprecedented multilingual and multicultural dynamic to North American society and its systems of formal schooling. On average, 225,000 immigrants of all ages have settled in Canada every year since 1990 [1]. Consequently, linguistic and cultural diversity now define a majority of the school-age population in many urban areas.

Adaptation to Western society can be a challenge for immigrant parents who must negotiate the physical and emotional stresses of establishing new lives for themselves and their family members in an unfamiliar culture. As Carreon, Drake, and Barton [2] observe:

To be successful parents, they must develop new understandings about the world, establish new social networks, acquire new forms of cultural capital (e.g., learning English), and learn new ways to function, including determining how to access medical and educational services for their children. (p. 3)

Among the many challenges confronting them, immigrant parents also must meet the expectations now integrated into the accountability protocols associated with state-supported public education regarding caregivers' roles in supporting their children's academic progress in and through school [3]. Undergirding these expectations is the assumption that caregivers will want to contribute to their children's education by "partnering" with professional educators to maximize the benefits from students' day-to-day schooling activities and experiences [4]. However, being involved in the education of their children requires that parents: (a) negotiate a common understanding with educational 
communities regarding appropriate roles and prerogatives of different stakeholder groups, and (b) establish social relationships with school teachers and administrators. Most parents find these processes daunting; for those parents who have recently migrated and have not yet mastered the societal language, they can be overwhelming [5].

Despite these challenges, the family-school relationship is central to any discussion of the ability of immigrant families to adapt to teaching and learning in new schooling contexts. Thus, while it is important for educators to facilitate the integration of immigrant children into the school system, building the capacity of their parents and families to become active partners in education is equally vital (e.g., [6]). Indeed, research on effective schooling identifies the home-school relationship as a key factor in a child's success at school. Some educational researchers have claimed that school initiatives that adopt a parents-as-partners approach aid in overcoming barriers to communication often perceived by teachers and parents in a culturally diverse schooling context (e.g., [7]).

Indeed, the concept of "parent involvement in education" has emerged in the literature as a common lens through which to explore and understand family-school relations. However, two distinct schools of thought have emerged with respect to the precise meaning of that concept. The first, more dominant, body of research begins its inquiry from the position of formal schooling, arguing that increased family involvement in the issues and relevancies of institutionalized schooling - for example, parent-teacher interviews, field trips, parent councils - will lead to stronger family-school relationships and, hence, improved student achievement (e.g., [4], [8]). The second, less dominant, body of work addresses issues of power and inequality in the family-school relationship and questions the normative notions that underlie the ideological framing through which teachers, parents, policymakers, and even researchers understand and practice the family-school relationship (e.g. [9], [10], [3]).

Investigations of the challenges that immigrant parents confront as they work to participate in their children's schooling generally align to the first framework described above. Investigations conducted within this framework have shown how the involvement of minority parents in the responsibilities of schooling has contributed to increased student achievement [11] including higher gains on reading and mathematics measures [12] and enhanced parental self-efficacy [13]. According to Pelletier and Brent: "high efficacy beliefs mediate the effect of stressors that may be associated with economic disadvantage and immigration, and promote adaptation that contributes to positive development” (p. 56).

\subsection{Context: The Parent Involvement AS Education Project}

The research initiative in which the study described in this article is embedded is sympathetic to the second framing of parent involvement. We named the initiative "Parent Involvement AS [not in] Education" (PIE) to emphasize both our commitment to building on the intellectual, experiential, and cultural resources and knowledge bases that exist within families, and our search to create a zone which equally fosters inter-generational learning and intellectual harnessing (that is, promoting parents' awareness of their own knowledge and ability to help their children).

The PIE project envisioned three main objectives: (a) to enhance the learning and achievement of immigrant, linguistic minority students by providing a complementary, communityreferenced venue for language and literacy learning; (b) to familiarize immigrant parents with the education system in which their children were enrolled and with school and provincial expectations for their children's academic performance, with a view to parents' active participation and advocacy in their children's public schooling; and (c) to promote an institutional climate that privileges diversity as a resource.

The school in which this project was embedded serves an ethnically, racially, and linguistically diverse student population in a dense urban context. The participants in our program included: (a) students and their parents; (b) teachers who volunteered to act as facilitators in the program; (c) school principals who monitored the program and interacted with the parents and students; (d) school board and resource people (e.g., reading/writing, math, science consultants); (e) settlement workers who accessed community services for families; (f) university-based researchers who studied the results of the instructional innovations; and, (g) secondary student volunteers from local high schools who were fulfilling the community-service component of their course of study by tutoring younger students.

The program's pedagogic framework started from the premise that the inter-generational learning space created a bridge between the expectations and requirements of language learning in schools and the real-life challenges encountered by immigrant adults and children while negotiating and functioning in a second language. The strategies and techniques facilitators used to promote cognitive engagement, therefore, carefully considered the question of appropriate content knowledge for child and adult learners. Consequently, students and parents had opportunities for working together and alone (i.e., in cross-age and age-specific venues). Typically, parents worked with their children for one hour of the two-hour after-school program and, for the other 
hour, the parents participated in presentations and discussions around topics that they identified as important (e.g., report cards, parent-teacher interviews, homework, health and child management issues, and the place of primary languages in their children's development).

Thus, while our project actively sought parent involvement, our definition of what that entailed included a community-referenced approach as part of a negotiated, evolving, and critically inclined research agenda. In cultivating an active partnership with caregivers, our interests were not so much in socializing parents to the agenda of mainstream schooling as in expanding our own and professional educators' understandings of: (a) the ways in which immigrant parents are involved in the everyday lives of their children, (b) their perceptions of their children's schooling and broader socialization/adaptation experiences, and (c) how family and community norms and resources shape these experiences.

\section{The Problem}

In this study, we were interested in interpreting, through parents' eyes and social spaces, the everyday experiences of their children. That is, we wanted to ascertain parents' perceptions of the social relations and processes that influenced and organized the everyday experiences of their children - in particular, their perceptions of the routines and practices that constituted their children's responsibilities as students and family members. We were also interested in gaining access to the semiotics of the New World experience as these presented to caregivers through the activities and dispositions of the children.

However, while we were confident in the community-referenced orientation of our project, we confronted a significant logistical problem in our efforts to ascertain caregivers' perspectives and input: a large majority of the adult caregivers we interacted with were barely (if at all) able to communicate in English; they most certainly were unable to contribute the level of nuance with regard to the organization of family members' everyday experiences that we needed in order to inform our interpretations as researchers and educators. Essentially, while the project was, to a large extent, about language, it was also seriously constrained by language. So, to find out more about the home lives of our students, we needed to find a way around this impasse.

\section{Method}

In this section we outline the use of photographic representation of participants' lives in the description of the study design and data collection methods.

\subsection{Overview: Photography as Text}

The "self-representation activities" [14] around photographic texts have been found to constitute an effective heuristic for tapping into participants' lives and their perspectives about the significance of social processes for these lived experiences and events [15], [16]. Some authors [17], [18] have used a "photo-voice method" to incorporate photography with participatory action research by having participants represent their social worlds using photographs which they then analyzed for meaning. The photographic text has been used as an effective visual presence for participants in a conversation [19] and has held referential value beyond the text through which readers, through association, can connect [20].

Drawing on the work of McCoy [19], who devised a method of activating visual texts by making text-reader conversations observable, we encouraged participants to use photographs to represent significant events in their children's lives. We further decided to organize the collection of visual data following predetermined themes that were linked to the goals of the research. We used preliminary glosses and subsequent photo-interview discussion sessions [21] to: (a) generate additional data, (b) further probe the ways in which participants perceived their life worlds and those of their children, and (c) ensure that caregivers participated in the analysis of the collected data. Finally, we used an open-ended approach to the discussion sessions to facilitate a process more aligned to a conversation among peers over a theme of interest than a formal interview [21].

\subsection{Design of the Study}

Participants in the study included 20 parents of Grade 5 and 6 students (aged 10 to 12 years). The authors chose four themes that we believed would draw out and illuminate parents' perspectives on issues and topics of interest to the children's educators. These themes, in the order presented, were: (a) learning at home and in the community, (b) homework, (c) my child's good day/bad day, and (d) O Canada.

Each family was given a disposable camera with 24 exposures. Parents were asked to capture, over a 4-week period, those aspects of their child's life that corresponded to their perceptions of the child's lived experiences around the four designated themes. The themes were introduced to caregivers by the study's coordinator, a Grade 6 teacher, at the project's weekly meetings. Parents were allotted a maximum of six exposures per theme. 
Using the language in which they felt most comfortable expressing their thoughts, parents were asked to use a Photography Log to record the exposure number, time, location, and rationale for taking each photograph. Where languages other than English were used, we elicited the help of translators. The photographs and log reflections were used as a basis for subsequent small- and large-group discussions (described more fully below). Field notes were taken and audio recordings were made of the group discussions. Selected portions of the recordings were transcribed in full.

\subsection{Data Collection and Analysis}

The study's design provided for three distinct data sources: (a) the photographs taken by participating parents constituted a primary data source; (b) written texts produced by parents in the form of photography logs provided a secondary data source; and (c) the photo-interview discussions (based upon the photographs and logs) generated a tertiary source of data. In the spirit of recursive data collection and analysis [22], the photo-interview discussions also constituted a primary strategy for data analysis, as parents recognized and identified common themes emerging from the data.

In the final two sessions of the project, caregivers shared their experiences and interpretations with one another. During the penultimate session, participants gathered around tables in their usual small groups, shared the photographs they had taken in sequential order, and discussed the larger issues that prompted the photographs. We used prompts to facilitate the discussions (e.g., Where is this photograph taken? What is your child doing here? Why did you choose to take this picture?). Toward the conclusion of this session, group members turned their attention to the common themes and shared experiences revealed by the photographic evidence.

In the last session photographs of the entire group were displayed at table clusters according to theme. Participants were given an additional opportunity to look at and reflect upon the photographs of other parents and to discuss the issues that the photographs raised according to theme. Here, however, we drew out parents' insights and understandings in large-group discussion, using prompts of a more summative and evaluative nature (e.g., What have you learned from this experience? What did you learn about your child through this project that might help us as teachers? How has your knowledge or perception of your child's home/school experiences changed? Which themes did you find the most informative?). Although the discussion was facilitated by these guiding questions, it was not controlled; that is, where conversation flowed, facilitators did not attempt to influence its direction.
We employed textual analysis to analyze the data from photographs, log entries, and transcripts from small- and large-group discussions. To begin, we coded primary (photographs) and secondary (log entries) data for generative topics within the four guiding themes. We used the principles of institutional ethnography for the analytic purpose of identifying and describing social relations and processes that extended beyond the boundaries of individual participants' localized experiences [23]. This approach is undergirded by the belief that the social organization of everyday life is a result of purposeful, concerted, and co-ordinated activities [23], and that the kinds of lives that are instantiated by actors are both facilitated and impeded by social structures such as rules, resources (including those of an ideational nature), and the relationships made available within institutions and social networks [24].

\section{Findings}

The primary purpose of this study was to discover recently immigrated parents' perceptions of their children's schooling and life experiences. As previously mentioned, data were collected and organized around four thematic headings. We chose to present here the findings from the three themes which, in our opinion, best represent the study's most significant findings.

\subsection{Learning at Home and in Community}

5.1.1. Language and culture. The photographic texts associated with this theme illuminated the importance that parents placed on supporting literacy practices in their homes. Photographs taken to illustrate this theme included children engaging with texts associated with school learning, surfing the Internet for the purpose of informing school or recreational projects, reading and reciting religious texts, and studying their first language as part of a larger strategy of linguistic and cultural maintenance. Parental support for and involvement in these home literacy projects was clearly evident in the photographic texts, as well as in the glosses and discussions.

The importance of the children's first languages was a significant concern for parents. The majority of them believed that: (a) the ability to speak, read, and write more than one language is inherently enriching; (b) maintaining their first language is important for retaining their heritage culture; and (c) speaking their language of origin is essential for maintaining relations with family members who did not emigrate. In the photo-interview discussions, in particular, parents expressed sorrow over the gradual first language attrition that they observed in their children. Together they shared various strategies for 
and difficulties in encouraging their children to value and use their heritage languages. However, most conceded that, because the language of media and education is English, it is difficult to avoid English at home.

Despite their concerns about the use and retention of their first language as an important component of learning, parent participants acknowledged the school's dominant role in coordinating many of the literacy activities in which their children are engaged while at home. One parent asked, "Is it okay to use my first language when I help my kids with math? Can I explain math problems in my own language?” Another parent felt that it was important for children to practice writing in their native language and suggested that teachers make time and space for children to do meaningful writing in their first language at school. A third parent suggested that teachers could sometimes give students material to translate into their first language, which would allow parents who are not fluent in English an opportunity to assist their children with homework.

The photographic texts also reveal how caregivers use social structures within their communities, such as community-based heritage language programs, to support their commitment to maintaining their mother tongues. For example, one photograph shows a group of children going to a community school to learn their first language. The log entry reads, "Mina and Arabic. Mina goes every Sunday to Valleys School to study Arabic "native language' with other kids in our community.”

5.1.2. Religious practice. Other photographs within this theme communicated many parents' views that an important dimension of learning at home and in the community is religious instruction and practice. Photographs depicted students involved in religious activities such as praying alone, with family members, or with community members in their age cohort. Figure 1 and the accompanying log entry confirm the important role that religious engagement plays in the learning that takes place at home.

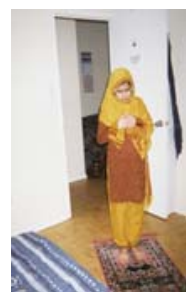

Figure 1. Idrisa learns all kind of worship and prayer from home

In the group discussions, parents emphasized the importance of religious practice for maintaining their connections to their cultural communities as well as for teaching their children how to live good lives and develop character. Figure 2 shows a child engaged in group meditation in a formal religious setting.

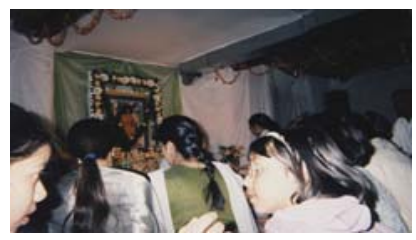

Figure 2. Meditation. Learning to sit quietly for $1 \frac{1}{2}$ hours and pray, sing songs and meditate with all age groups

In their discussions, parents elaborated on how they used community structures to co-ordinate their children's religious and cultural education while fostering first language development. They felt that these community venues reinforced the legitimacy of their own values related to cultural and linguistic maintenance, and provided students with important social networks for learning.

5.1.3. Housework. Photographs within the learning at home and in community theme also highlighted the parents' commitment to ensuring that their children develop basic life skills, such as the ability to contribute to the domestic economies of homes. For example, the entry in the photography log for Figure 3 reads, "Idrisa learns all kinds of household work like washing, cleaning, and organizing from her mom.”

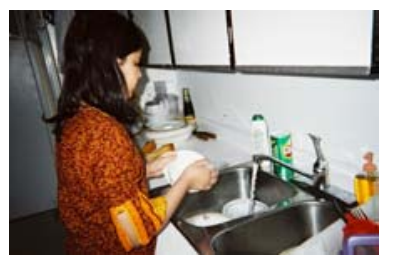

Figure 3. Idrisa learns all kinds of household work like washing, cleaning, and organizing from her mom

Another photograph illustrates a child engaged in the activity of grocery shopping. In subsequent discussion, the child's mother elaborated on her perspective on the importance of providing opportunities for her child to make choices for the family.

5.1.4. Caring for community. The importance that parents placed on their children developing a sense of civic responsibility emerged through the photographic texts and in the discussion sessions. Various photographs depict children engaged in activities such as recycling household objects, caring for the environment by collecting strewn garbage from apartment grounds, and helping less fortunate community members with chores. A photograph 
entitled "Helping in Canada" (Figure 4) shows a young girl standing beside a relatively large bin recycling what appears to be paper material. The accompanying log entry highlights the enthusiasm with which the girl embraces the activity.

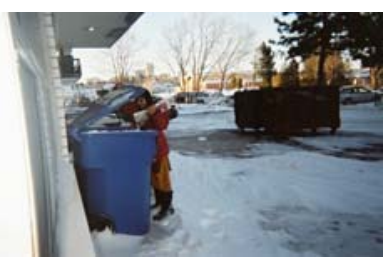

Figure 4. Helping in Canada. When Idrisa sees other people do recycling she really likes it and tries to make it her habit

Another parent's log entry affirms the value of helping community members: "Caroline doing dishes for an elderly woman where we live. She often helps this person that is unable to do things herself. Shows she is caring and willing to give of herself to help others. Learning to be generous.”

5.1.5. Cultural literacy. Parents observed that the activity of engaging in this visual literacy project opened their eyes to different types of learning events that they took for granted in their children's daily lives. For example, the parent who took the photograph entitled "Children learn discipline at school bus stop" (Figure 5) had not previously realized that, for her child, the formal school day began with this event. In her discussion group she commented:

I think when children usually go by bus they usually learn discipline because on the bus they are all in one line otherwise they are all gathered here and there playing in the snow. So when the bus comes, they line up. They line up otherwise they all playing in the snow. Only when they see the bus comes in the street they all line up.

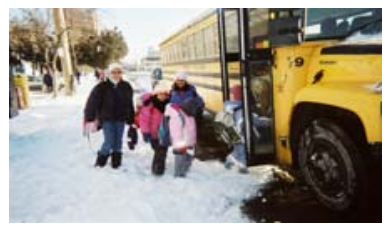

Figure 5. Children learn discipline at school bus stop

This parent, who had also taken several photographs of her child engaged in recycling activities, later expanded:

When I asked [name of child] what did you learned from the community, I had no idea at that time ... I was so surprised in a moment she answered me. "Recycling, going on the school bus” [short pause] I was so happy because I did not know about these little things. I saw my daughter do this, do that, but I did not realize that those things are so important [short pause] these things lay hidden before this project.

In Canadian society, a significant degree of socialization of children occurs outside of processes associated with parenting and formal schooling. The photographs provided textual representations of key events associated with important socio-cultural ways of being into which children in Western society are acculturated. For immigrant parents, gaining insight into the seminal role of these activities and events represented an acquisition of cultural literacy.

\subsection{Homework}

The sharing of the homework photographs drew out parents' perceptions of the nature of homework within the context of Western schooling and the resources that students must call upon to complete related assignments. Group discussions revealed parents' varying orientations toward different aspects of school-assigned work and their roles in the accountability process.

5.2.1. The collaborative nature of homework. The photographs provided effective heuristics for parents to engage in discussion about ways in which they believed they facilitated - or encountered barriers that prevented them from facilitating - their children's academic success. Parents cited barriers such as conflicting work schedules, lack of fluency in the language of instruction, and lack of familiarity with the school curriculum. In her photography log, one mother commented: "This picture shows Caroline struggling with French translation and spelling looking up words. I feel bad because I haven't taught any French in my home and I do speak the language.” In small-group discussion, another parent volunteered: "I try to help them with their homework. When our kids learn we learn. I don't know some things. If I don't know, we Google it. We can solve problems together."

Certainly the discussions around this theme supported the observation by Carreon and colleagues [25] that

parents' educational engagement and

presence within the home space is a practice through which parents can construct a self-identify as one who supports their children's schooling. (p. 11)

However, the amount and kinds of support adult participants were able to provide for their children's school learning varied. This variation was caused by factors such as: parents' employment status, which 
influenced when and for how long they could be available to help their children during non-school hours; and their familiarity with and access to resources such as computers.

One photograph in particular sparked a group discussion that revealed parents' understandings that their children's academic support networks needed to extend beyond their immediate family circles. The photograph (Figure 6), which shows a child talking over the phone to clarify a homework assignment, illustrates an important way in which children learn and are supported by their peers.

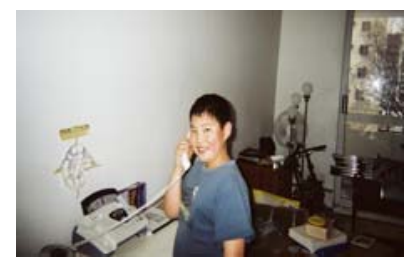

Figure 6. Calling a Friend. I am communicating with others

5.2.2. Computers and library outings. Many photographs depicted the children using computers. The number and variety of photographs under the first two themes related to computer use reflects a socio-cultural expectation, on the part of both the school and families, that children will develop technological competencies alongside other aspects of academic literacy. The value that caregivers placed on computer access was reflected in both the photographs and subsequent small- and large-group discussions. As well, in their logs and verbal exchanges, parents revealed that many families supplemented the resources available in the home through frequent outings to the local public library. Parents appreciated the availability of these public resources, perceiving them as important vehicles for their children to attain and reinforce the knowledge and skills that were increasingly necessary to succeed academically.

5.2.3. Homework can be messy. Several photographs (Figure 7) and logs revealed a consensus that the creative process involved in school-related learning can be untidy. Responses to this aspect varied. Parental comments ranged from somewhat negative ("very messy work - paper and food on the table - I don't like this mess") to very positive ("sometimes mess gives a person more ideas").

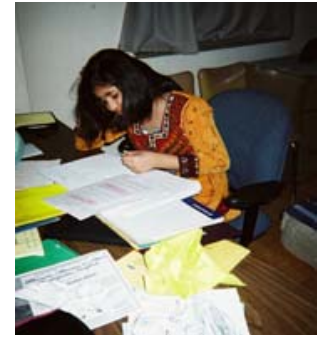

Figure 7. Lots of mess while doing homework

In addition to computers, photographs of children doing homework revealed the presence of many other material resources - lined writing paper, colored manila paper, pens, lead pencils, glue sticks - that were used to support school learning. Regardless of where parents weighed in on the tolerance-for-mess continuum, these various material items were viewed as necessary support for the daily routines associated with homework activity.

\subsection{O Canada}

Here we highlight the diverse perspectives that reflect the Canadian experience of new immigrant families in this study.

5.3.1. Winter. The thematic rubric $O$ Canada generated insights into immigrant family members' New World experiences. Overwhelmingly, for recently translocated families, Canada evoked the image of winter. Many of the photographs taken to illustrate this theme depicted students playing in the snow. As evidenced in Figures 8 and 9, these associations generally were positive.

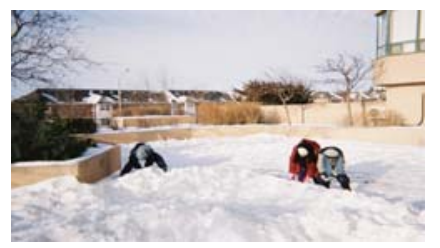

Figure 8. The Snow. To show the Canadian weather in winter and how our kids practice its activities

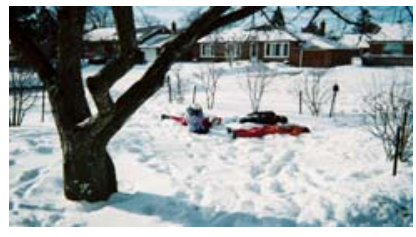

Figure 9. Friends. Joanna was so happy to be playing in the snow with her friends and her sister. She enjoyed talking and laughing with them and being happy

5.3.2. Longing for family. However, there was a more sombre aspect to the images associated with 
the expatriation and repatriation subject position. Indeed, many photographs revealed caregivers' recognition that, in terms of parenting decisions, the family's immigration to Canada was both difficult and complex. In both large- and small-group discussions, participants emphasized that their main motivation for immigrating was to provide their children with opportunities to secure a better economic future than they had been able to enjoy thus far - opportunities that they associated with Canadian schooling. However, despite these significant incentives, parents acknowledged that longings for family and friends in their countries of origin constituted an unavoidable reality of their children's Diaspora experiences. These feelings of loneliness and loss are captured poignantly in Figure 10 and its accompanying log entry.

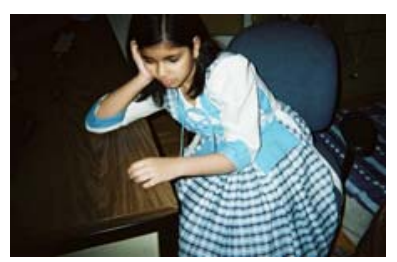

Figure 10. There is some hidden feeling of loneliness in this new country. Idrisa misses her grandparents, cousins, uncles and aunt a lot

In the small group discussion sparked by this photo, Idrisa's mother revealed that her daughter was reluctant to share these feelings of melancholy and longing with others. Before her involvement with this project, Idrisa's mother had thought that her family were the only ones to be suffering such ennui:

After I have passed one year in this country, and you know I think one month before, Idrisa said something quietly. I said, "What happened?" She started crying. She said, "What can I do here? I miss my grandparents." I was shocked....I realized that there are some feelings that she doesn't share with us...Last year was the very worst for me. There were times that I thought we would have to go back, really. I told my husband no need to stay here. We got everything there [home country] if we go back. We are staying here only for our children. If our children spoil there is no bigger loss than that.

In addition to feelings of loss of extended family connections, another significant challenge that parents associated with migration and acculturation related to changes in the family dynamic. Parenting roles and parents' sense of identity/positionality with their families appear to have been significantly influenced by factors such as: changes in the employment status of one or both parents, lifestyle changes related to under-employment, and separation from spouses due to immigration processes. For example, one parent commented:

We had everything back home. Since here my husband works two jobs. Sometimes my husband gets back from work and he is so tired he can do nothing with the children. I say sorry. Only stay for the meal. You have to try because this is the only occasion that we share our family happiness.

5.3.3. Negative encounters. Participants commented on the need to help their children navigate difficult social contexts, such as dealing with bullying behavior and acts of discrimination. In her smallgroup conversation, one parent discussed her painful experience as she helplessly watched her child's confidence erode as a result of being persecuted by peers at school:

I thought it was a mistake to come to

Canada. I did not know who to talk to about

problems. For 9 months I did not know who

to talk to until I received a pamphlet from

school and it said to discuss [bullying

problems] with teacher.

This same parent went on to express how knowledge made a difference in her and her child's circumstances, how she handled the situation, and how it was resolved.

The difficulties experienced by recently translocated families while navigating new social contexts are well documented [26]. Studies describe family members' experiences in coping with loss and family change [27] as well as with racism [28]. Original to the findings of this particular study is participants' acknowledgment of the positive role played by the school in families' successful negotiation of these difficulties. Parents found information distributed by the school (in the form of pamphlets, advertisements for workshops, newsletters, etc.) enormously helpful and appreciated that many of these resources were made available by the Ontario Ministry of Education and/or by social and community agencies. Indeed, caregivers expressed the view that, had it not been for dissemination through the school, they would have remained ignorant about provincial norms and board policies concerning bullying and protocols for student conduct in general.

\section{Discussion}

The photographs, photography logs and discussion sessions that constituted the data collection strategy for this study served two important functions: (a) They documented the seminal culture-filtered perspectives and understandings held by caregivers as they reflected upon their children's educational experiences in their newly adopted country; and (b) they provided a 
crucial window into how community cultural wealth may be activated and expressed in the everyday lives of immigrant students as they and members of their support networks seek to navigate the challenges associated with coming to terms with an unfamiliar society and its social structures.

Beyond these anticipated functions, this activist research project resulted in a crucial outcome: it created new understandings and fostered empathy between immigrant parents and professional educators. Despite the goodwill of the study's participants, these dispositions simply were not available to respective stakeholders at the start of the project. However, the photographs, glosses, and group discussions opened two distinct channels of understanding. Firstly, they served as conduits through which professional educators could effectively access domains of knowledge related to those spheres of influence in children's lives that are not normally discovered through standard schooling practices. Secondly, and equally importantly, they helped immigrant parents to access, and to better understand, the diverse resources that children call upon as they navigate various aspects of their Diaspora experiences. These aspects include: (a) their encounters with peers and community members; (b) the evolving dynamics, roles, and routines within their families; and (c) the syncretic effects of the interactions among heritage, new languages, and diverse cultural practices [29]. Certainly, all of these elements were represented in the data from the start; however, the use of the photographs as points of reference in the logs and in subsequent group discussions provided a strong catalytic effect for participants in terms of working through and extending their understandings.

For professional educators, this study also provided valuable insights into the extent to which the school context extends beyond the parameters of the classroom and the formal curriculum to influence the socialization of immigrant students and their families. It is evident from the testimony of parents that schooling practices and structures were tied significantly to many aspects of the lives of students and caregivers, including: (a) their social relations, (b) their ongoing interpretation of linguistic and cultural cues [30], and (c) their opportunities to build new forms of and contexts for literate engagement of cultural processes [31]. These syncretic effects range from relatively simple things (such as family trips to the library on weekends for the purposes of informing and completing school projects) to more complex elements (such as parents' complicity in the standardization of their children's learning through their partnering in the state accountability exercises). Finally, participants' responses to the visual literacy project indicated that caregivers both valued and enjoyed the opportunities provided to gain access and give voice to what they knew about their children's lives and their lived experiences. Indeed, for most participants, the venue fulfilled an important role in the development of positive relationships between caregivers and the school. As parents experienced their contributions being valued, they became increasingly motivated to build ongoing relationships with school staff and to establish their presence within the school culture.

\section{Conclusion}

We decided to use photography as a strategy for getting around the linguistic problems inherent in conducting research that involved gaining access to the perspectives of non-native speakers of the societal language. As the project progressed, it became clear that the photographs functioned not simply as representational icons that substituted for verbal texts but also as powerful heuristics that drove participants' thinking about the psychological and social worlds of their children and families. These heuristics served to highlight how the lives of immigrant children and their families are coordinated through daily routines involving family, school, and community.

The results of our study reveal that the school, apart from the role it plays in the academic socialization of children, is a powerful vehicle for the dissemination of crucial information on societal norms, values, and practices. In the context of this particular study, embedded within an activist research agenda that privileged diversity as a resource, we found the association between the school and newly migrated families to be generally beneficial. Although we are persuaded of the value of visual literacy strategies in elucidating the perspectives of those whose voices are frequently marginalized within extant institutional structures, we are not so unrealistic as to expect that such favourable conditions for the empowerment of the sub-altern exist in most schooling contexts.

\section{References}

[1] OECD Programme for International student Assessment. (2003). Where immigrant students succeed: A comparative review of performance and engagement in PISA 2003. Retrieved February 18, 2006, http://www.pisa.oecd.org.

[2] G. P. Carreon, C. Drake, and A.C. Barton, "The importance of presence: Immigrant parents' school engagement experiences.” American Educational Research Journal, SAGE Journals, Washington, DC, 2005.42(3), pp. 465-499.

[3] Griffith, A. and Smith, D., Mothering for schooling. Routledge/Taylor Francis, New York, 2005.

[4] Epstein, J. L., Coates, L., Salinas, K. C., Sanders, M. G. and Simon, B. S., School, family and community partnerships: Your handbook for action. Corwin, Thousand Oaks, California, 1997. 
[5] S. R. Schecter, and D. L. Sherri, “"Value Added?» Teachers' investments in and orientations toward parent involvement in education." Urban Education, SAGE, Baton Rouge, LA, 2009, 44 (1), pp. 59-87.

[6] Schecter, S. R., \& Cummins, J. (2003). Multilingual education in practice: Using diversity as a resource. Portsmouth, NH: Heinemann.

[7] Pelletier, J., \& Brent, J. M. (2002). Parental participation in children's school readiness: The effects of parental self-efficacy, cultural diversity, and teacher strategies. International Journal of Early Childhood, 34(1), 45-60.

[8] L. A. Rosado, "Promoting partnerships with minority parents: A revolution in today's school restructuring efforts." Journal of Educational Issues of Language Minority Students, 2004, 14, pp. 241-244.

[9] David, M. E., Edwards, R., Hughes, M., \& Ribbens, J. (1993). Mothers and education, inside out?: Exploring family-education policy and experience. London: St. Martin’s Press.

[10] Delpit, L. (1995). Other people's children: Cultural conflict in the classroom. New York: New Press.

[11] Hill, N. E., Castellino, D. R., Lansford, J. E., Nowlin, P., Dodge, K. A., Bates, J. E., et al. (2004). Parent academic involvement as related to school behaviour, achievement, and aspirations: Demographic variations across adolescence. Child Development, 75(5), 1491-1509.

[12] Garcia, D. C., \& Hasson, D. J. (2004). Implementing family literacy programs for linguistically and culturally diverse populations: Key elements to consider. School Community Journal, 14(1).

[13] Pelletier, J., \& Brent, J. M. (2002). Parental participation in children's school readiness: The effects of parental self-efficacy, cultural diversity, and teacher strategies. International Journal of Early Childhood, 34(1), 45-60.

[14] Luttrell, W., Pregnant bodies, fertile minds: Gender, race, and the schooling of pregnant teens. Routeledge, New York, 2003.

[15] D. Secondulfo, The meaning of things: A working field for visual sociology. Visual Sociology, 1997, 12(2), 33-45.

[16] Wagner, J., Introduction: Information in and about photographs. In J. Wagner (Ed.), Images of information: Still photography in the social sciences. Sage Publications, Beverly Hills, CA, 1979, pp.11-22.

[17] C. C. Wang, "Photovoice: Concept, methodology, and use for participatory needs assessment." Health Education \& Behavior, SAGE, Ann Arbor, MI, 1997, 24(3), 369-387

[18] Wang, C. C., Using Photovoice as a participatory assessment and issue selection tool: A case study with the homeless in Ann Arbor. In M. Minkler \& N. Wallerstein (Eds.). Community-based participatory research for health Jossey-Bass, San Francisco, 2003, pp. 179-196.
[19] L. McCoy, "Activating the photographic text." In M. Campbell, and A. Manicom (Eds.), Knowledge, experience, and ruling relations: Essays in the social organization of knowledge. University of Toronto Press, Toronto, ON, 1995, pp. 181-192.

[20] Smith, D. E., The conceptual practices of power: A feminist sociology of knowledge. Northeastern University Press, Boston, 1990.

[21] M. Cappello. "Photography as a data generation tool for qualitative inquiry in education.” Paper presented at the Annual Meeting of the American Educational Research Association, Seattle, WA, April 2001.

[22] Goetz, J., and Lecompte, M., Ethnography and qualitative design in educational research. Academic Press, Orlando, Florida, 1984.

[23] Campbell, M. and Gregor, F. Mapping social relations: A primer in doing institutional ethnography. Garamond Press, Aurora, ON, 2002.

[24] Smith, D. E., Institutional ethnography: Sociology for people. Rowman \& Littlefield, Lanham, MD, 2005.

[25] G. P. Carreon, C. Drake, and A.C. Barton, "The importance of presence: Immigrant parents' school engagement experiences.” American Educational Research Journal, SAGE Journals, Washington, DC, 2005.42(3), pp. 465-499.

[26] K. M. Perreira, M. V. Chapman, and G. L. Stein, "Becoming an American parent: Overcoming challenges and finding strength in a new immigrant Latino community." Journal of Family Issues, SAGE, Gainesville, FL, 2006, 27(10), pp. 1383-1414.

[27] D. Sciarra, "Intrafamilial separations in the immigrant family: Implications for cross-cultural counselling." Journal of Multicultural Counseling and Development, Antioch University, Birmingham, AL, 1999, 27(1), 31-41.

[28] C. G. Coll, and L. A. Szalacha,"The multiple contexts of middle childhood (Children of immigrant families)." The Future of Children, Princeton Brookings, Princeton NJ, 2004, 14(2), pp. 81-98.

[29] E. Gregory, T. Arju, J. Jessel, C. Kenner, and M. Ruby, "Snow white in different guises: Interlingual and intercultural exchanges between grandparents and young children at home in east London.” Journal of Early Childhood Literacy, SAGE, Sheffield, UK, 2007, 7(1), pp. 5-25.

[30] Smith, D. E., Institutional ethnography as practice. Rowman \& Littlefield, Lanham, MD, 2006.

[31] S. Long, D. Volk, and E. Gregory, "Intentionality and expertise: Learning from observations of children at play in multilingual, multicultural contexts." Anthropology and Education Quarterly, Wiley -Blackwell, Hoboken, NJ, 2007, 38(3), pp. 239-259. 